\title{
Avaliação do dímero D (D-Di) na doença hipertensiva específica da gravidez (DHEG)
}

\author{
D-dimer plasma levels assessment in preeclampsia
}

Luci Maria Sant'Ana Dusse

Lauro Mello Vieira

Maria das Graças Carvalho

unitermos

Doença hipertensiva

específica da gravidez

Dímero D

\section{resumo}

A doença hipertensiva específica da gravidez (DHEG), na sua forma pura, caracteriza-se pelo

aparecimento, em grávida normotensa, após a vigésima semana de gestação, da tríade sintomática: hipertensão, proteinúria e edema. A DHEG está associada a vasoconstrição generalizada, anormalidades da coagulação e deposição de fibrina na microcirculação da placenta. A fibrina compromete a perfusão adequada da placenta, contribuindo para a prematuridade, o baixo peso fetal e a mortalidade neonatal. Os dímeros $D(D-D i)$ constituem os menores fragmentos dos produtos de degradação da fibrina (pdf) e são produzidos após a lise, pela plasmina, da ligação cruzada da fibrina. Níveis plasmáticos aumentados de D-Di indicam tanto uma exacerbação da formação de fibrina como um aumento da ação da plasmina. O presente trabalho teve por objetivo avaliar e comparar os níveis plasmáticos de D-Di, obtido por Elisa (Stago) em gestantes-controle $(n=26)$, gestantes com DHEG nas formas leve e moderada $(n=23)$ e gestantes com DHEG na forma grave $(n=20)$, visando a investigar a possível utilização desse marcador laboratorial para diagnóstico e/ou prognóstico da doença. As médias e os desvios padrões obtidos para os três grupos avaliados foram $1.146,6 \pm 311,2 ; 1.060,3 \pm 259,2$ e 1.497, $8 \pm 435,3 \mathrm{ng} / \mathrm{ml}$, respectivamente. A análise estatística das médias dos resultados obtidos revelou um aumento significativo de D-Di plasmático no grupo com DHEG grave, comparando-se aos grupos com DHEG leve/ moderada $(p<0,001)$ e grupo-controle $(p<0,01)$. Considerando-se os resultados obtidos, pode-se sugerir que há uma exacerbação da coagulação na forma grave da DHEG e que o sistema fibrinolítico está atuante buscando remover a excessiva quantidade de fibrina formada. O D-Di constitui uma potencial ferramenta para se avaliar a gravidade da doença. 


\section{Introdução}

A doença hipertensiva específica da gravidez (DHEG), na sua forma pura, caracteriza-se pelo aparecimento, em grávida normotensa, após a vigésima semana de gestação, da tríade sintomática: hipertensão, proteinúria e edema. A DHEG é uma doença incurável, exceto pela interrupção da gravidez, e pode evoluir para quadros ainda mais complexos como eclâmpsia, síndrome Hellp (haemolysis, elevated liver enzyme actvity, low platelets) e coagulação intravascular disseminada (CID) $(5,14)$. Esta doença está associada a vasoconstrição generalizada, anormalidades da coagulação e deposição de fibrina na microcirculação da placenta. A fibrina compromete a perfusão adequada da placenta, contribuindo para a prematuridade, o baixo peso fetal e a mortalidade neonatal (5).

Nos últimos anos, tornou-se disponível nos laboratórios clínicos uma série de marcadores visando avaliar o processo da coagulação in vivo. Os dímeros $\mathrm{D}$ (D-Di) constituem os menores fragmentos dos produtos de degradação da fibrina (pdf) e são produzidos após a lise, pela plasmina, da ligação cruzada da fibrina (11). Em determinadas circunstâncias, o excesso de plasmina formado e não-antagonizado pela antiplasmina pode agir sobre o fibrinogênio plasmático, transformando-o em produtos de degradação do fibrinogênio (PDF). Níveis plasmáticos aumentados de D-Di indicam tanto uma exacerbação da formação de fibrina como um aumento da ação da plasmina (7). O mecanismo de formação de D-Di está demonstrado na Figura 1.

O presente trabalho teve por objetivo avaliar e comparar os níveis plasmáticos de D-Di na DHEG, em diferen-

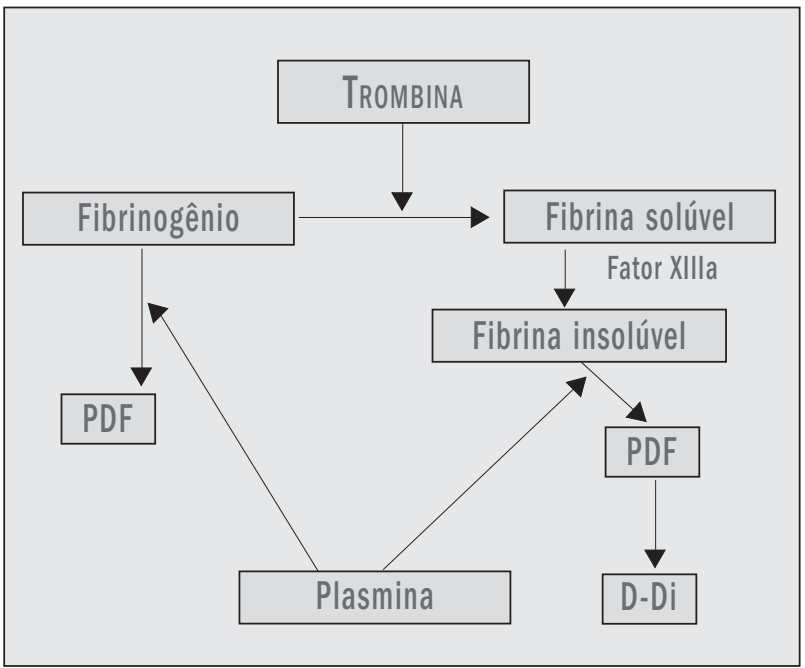

Figura 1 - Mecanismo de formação de dímeros $D$ tes formas clínicas, visando a investigar a possível utilização desse marcador laboratorial para diagnóstico e/ou prognóstico da doença.

\section{Metodologla}

Este estudo foi previamente analisado, sob os pontos de vista ético e formal, pela Comissão de Ética da Maternidade Odete Valadares, em Belo Horizonte, Minas Gerais, onde as gestantes foram selecionadas. Todas as gestantes envolvidas no estudo foram devidamente informadas dos objetivos da pesquisa e o consentimento livre e esclarecido foi obtido em todos os casos.

Para este estudo foram constituídos três grupos: o primeiro, de gestantes normotensas, grupo-controle $(n=26)$, e o segundo e terceiro, de gestantes apresentando DHEC (forma pura), sendo o segundo formado por gestantes com a doença nas formas leve/moderada $(n=23)$ e o terceiro, na forma grave $(n=20)$.

Os critérios de inclusão das gestantes no grupo-controle foram: pressão sistólica/diastólica inferior a 120/ $80 \mathrm{mmHg}$, sem qualquer história de hipertensão e ausência de proteinúria.

Para o grupo de gestantes apresentando a DHEG pura, foram utilizados os critérios determinados pelo Comitê de Terminologia do Colégio Americano de Obstetras e Ginecologistas (9), que incluem o surgimento de hipertensão gestacional associada a proteinúria ou edema generalizado ou ambos, a partir da vigésima semana de gestação, em gestantes até então normotensas, conforme os seguintes parâmetros:

a) hipertensão foi considerada a partir de níveis tensionais iguais ou superiores a $140 \mathrm{mmHg}$ para a pressão arterial sistólica ou $90 \mathrm{mmHg}$ para a pressão arterial diastólica, em no mínimo duas ocasiões, com intervalo superior a quatro horas entre as determinações;

b) proteinúria foi definida como anormal quando igual ou superior a $0,3 \mathrm{~g} / \mathrm{l}$, em urina de 24 horas, ou maior que (+), em amostras isoladas, pelo método qualitativo de fita;

c) o edema foi considerado patológico apenas quando havia acometimento das mãos e/ou da face e nos quadros de anasarca.

A classificação da DHEG como leve, moderada ou grave foi previamente feita pela equipe obstétrica, considerando os valores da pressão sangüínea e da proteinúria, conforme definido por Davey e MacGillivray, 1988 (4). 
Os critérios de exclusão, comuns aos três grupos, foram: obesidade, presença de doenças intercorrentes como diabetes, câncer, doenças cardiovasculares, doenças renais, doenças auto-imunes, doenças hepáticas, distúrbios da coagulação (incluindo história anterior de manifestações clínicas sugestivas de hipo ou hipercoagulabilidade) e presença de sangramento de qualquer natureza.

Uma ficha clínica visando a certificar que as participantes do estudo atendiam todos os critérios de inclusão e de exclusão estabelecidos foi preenchida em todos os casos.

\section{Amostra biológica}

Foram coletadas de cada gestante, no terceiro trimestre da gravidez, amostras de $2,7 \mathrm{ml}$ de sangue, por punção venosa, diretamente em tubos a vácuo (Becton Dickinson), e contendo citrato de sódio a 3,2g\%, devidamente identificados. As amostras foram centrifugadas a 3.000rpm, por dez minutos; os plasmas foram transferidos para tubos Eppendorf e acondicionados a $-20^{\circ} \mathrm{C}$, até o momento da realização do teste.

\section{Avaliação laboratorial}

A determinação dos níveis plasmáticos dos dímeros $\mathrm{D}$ foi obtida pelo método Elisa, utilizando-se o conjunto diagnóstico Stago, seguindo-se rigorosamente as instruções do fabricante. A concentração de D-Di de cada plasma testado foi obtida interpolando-se a média das leituras das duplicatas em uma curva-padrão. A curva-padrão foi traçada utilizando-se um padrão de concentração conhecida $(1.120 \mathrm{ng} / \mathrm{ml})$, fornecido pelo fabricante, e quatro diluições sucessivas deste, preparadas no momento do teste $(1: 2,1: 4,1: 8$ e 1:16), correspondentes, respectivamente, a $560,280,140$ e $70 \mathrm{ng} / \mathrm{ml}$.

\section{Análise estatística}

A análise estatística foi realizada empregando-se 0 software Systat v.8.03.

A existência de diferenças significativas entre os grupos foi apurada por análise de variância (Anova) e pela localização da diferença pelo teste de Fisher/LSD (least significance difference). Um valor de $p<0,05$ foi considerado estatisticamente significante.

\section{Resultados}

As médias e os desvios padrões obtidos para os três grupos avaliados foram 1.146, $6 \pm 311,2 ; 1.060,3 \pm 259,2$ e $1.497,8 \pm 435,3 \mathrm{ng} / \mathrm{ml}$, respectivamente. A dispersão dos valores obtidos nos três grupos avaliados pode ser observada na Figura 2.

A análise estatística das médias dos resultados obtidos revelou um aumento significativo de D-Di plasmático no grupo com DHEG grave, comparando-se aos grupos com DHEG leve/moderada $(p<0,001)$ e grupo-controle $(p<0,01)$. Entre os grupos com DHEG leve/moderada e controle não foi observada diferença entre as médias.

\section{Discussão e conclusões}

Mulheres grávidas apresentam, normalmente, ativação do sistema hemostático, o que constitui um importante mecanismo protetor contra sangramentos excessivos por ocasião do parto (8). No presente estudo, os resultados obtidos para o grupo-controle, constituído de gestantes normais, confirmam esta assertiva, considerando a obtenção de valores significativamente mais elevados que o limite superior da faixa normal para dímero $D(<400 \mathrm{ng} / \mathrm{ml})$. Valores elevados de D-Di na gestação normal foram anteriormente observados $(3,12)$ e Bellart et al. (1) relataram um aumento progressivo de D-Di ao longo da gestação, com níveis máximos no momento do parto.

A determinação de D-Di tem sido largamente empregada para exclusão de trombose venosa profunda (TVP) e de acidentes tromboembólicos. Os testes imunoenzimáticos deste marcador possuem aproximadamente 100\% de sensibilidade e $60 \%$ de especificidade, o que confere um alto valor preditivo negativo para o diagnóstico de TVP $(6,10)$. Além da TVP, um aumento de D-Di em pacientes com condições clínicas relacionadas à formação de fibrina,

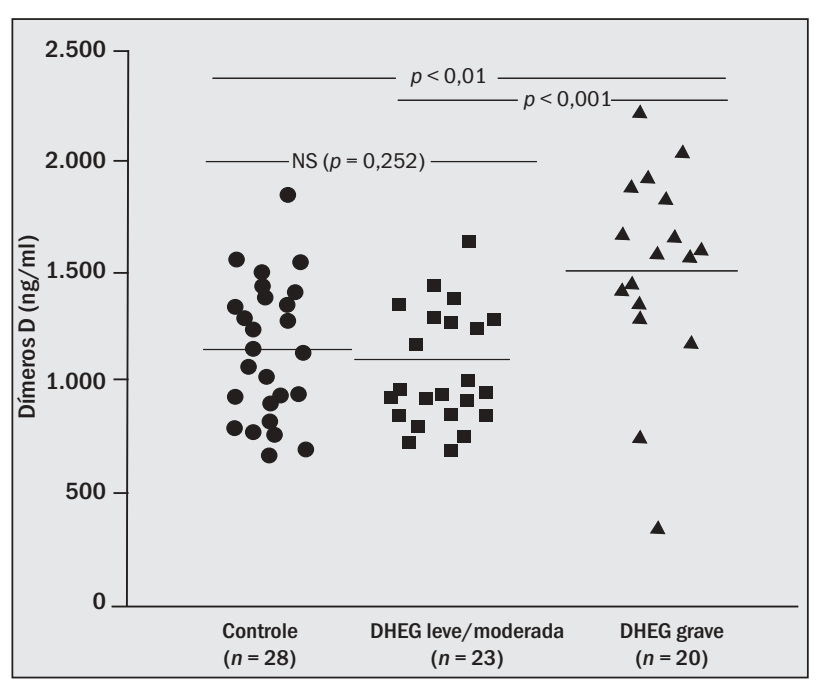

Figura 2 - Niveis plasmáticos de dímeros D/D-Di $(\mathrm{ng} / \mathrm{ml})$ determinados por Elisa. A linha horizontal mostra a média dos valores obtidos 
refletindo a lise in vivo da fibrina estável, tem sido observado. Estas condições incluem embolia pulmonar (EP), câncer, pós-operatório, trauma, coagulação intravascular disseminada (CID), entre outras $(6,10)$.

Em concordância com os resultados obtidos por Schjetlein et al. (13), no presente estudo foi verificado um aumento de D-Di apenas na forma grave da DHEG. Considerando que o D-Di representa o último produto de degradação da fibrina pela plasmina e que a sua presença no plasma é um marcador indireto da ativação da coagulação seguida da fibrinólise reativa (7), pode-se inferir que há uma coagulabilidade sangüínea exacerbada na forma grave da DHEG.

Concluindo, os resultados obtidos neste estudo sugerem uma exacerbação da coagulação na forma grave da DHEG, que o sistema fibrinolítico está atuante, buscando remover a excessiva quantidade de fibrina formada e, finalmente, que o D-Di constitui uma ferramenta potencial para auxiliar o diagnóstico precoce da doença e definir o agravamento desta, conforme proposto anteriormente por Trofatter et al. (15). No entanto, em decorrência do número limitado de gestantes avaliadas, os resultados obtidos não permitem concluir sobre um ponto de corte acima do qual seria sugestivo de diagnóstico de DHEG grave. O monitoramento dos níveis de D-Di ao longo da gravidez em gestantes com história prévia de DHEG e, portanto, candidatas potenciais a manifestar novamente a doença, torna-se altamente desejável para definir os níveis de D-Di, que podem sugerir o agravamento da doença.

\section{Agradecimentos}

À Fundação de Amparo à Pesquisa do Estado de Minas Gerais (Fapemig); à Pró-Reitoria de Pesquisa da UFMG; às equipes de ginecologia/obstetrícia e de enfermagem da Maternidade Odete Valadares, em Belo Horizonte, MG, de modo especial ao dr. Antônio Fernandes Lages.

\section{Referências}

1. Bellart, J. et al. Fibrinolysis changes in normal pregnancy. J. Perinat. M ed., 25: 368-72, 1997.

2. Boneu, B. et al.D-D imers, thro mbin antithrombin III complexes and prothrombin fragments 1+2: diagnostic value in clinically suspected deep vein thro mbosis. Thromb. Haemost., 65: 28-32, 1991.

3. Bremme, K. \& Blombäck, M. Hemostatic abnormalities may predict chronic hypertension after preeclampsia. Gynecol. Obstet. Invest., 41:20-6, 1996.

4. Davey, D.A \& \& MacG illivray, I.The classification and definition of the hypertensive disorders of pregnancy. Am. J. Obstet. Gynecol., 158: 892-8, 1988.

5. Delascio, D. Hipertensão na gravidez. São Paulo: Savier, 1983.

6. Gaffney, P.J. Monoclonal antibodies to crosslinked fibrin degradation products (XL-FDP). Evolution in a variety of clinical conditions. Br. J. Haematol., 68: 91-6, 1998.

7.G affney,P.:;Joe,F.\& Mahmoud,M.G iant fibrin fragments derivated from crosslinked fibrin: structure and clinical implication. Thromb. Res., 20: 647-62, 1980.

8. Gilabert, J. et al. Mo dificacio nes de la hemostasia en obstetricia. Rev. Iberoamer.Tromb. Hemostasia, 8: 102-12, 1995.
9. H ughes, E.C . Obstetric-gynecology terminology. Philadelphia: F.A D avis, 1972

10. Kelly, J. et al. Plasma D-Dimers in the diagnosis of venous thro mboembolism. Arch. Intern. M ed., 162: 747-56, 2002.

11.0 tt, P. et al.A ssessment of D-D imer in plasma: diagnostic value in suspected deep venous thrombosis of the leg. Acta M ed. Scand., 224: 263-7, 1988.

12. Proietti, A.B. et al. A ssessment of fibrin(ogen) degradation products in preeclampsia using immunoblot, enzyme-linked immunosorbent assay, and latex-bead agglutination. Obstet. Gynecol, 77(5):696-9, 1991.

13. Schjetlein, R.; H augen, G \& \& W islo ff, F. Markers of intravascular coagulation and fibrinolysis in preeclampsia:association with intrauterine growth retardation. Acta Obstet.Gynecol. Scand., 76: 541-6, 1997.

14. Sibai, B.M.; Ramadan, M.K. \& U sta, I. Maternal morbidity and mortality in 442 pregnancies with hemolysis, elevated liver enzymes, and low platelets H ellp syndrome. Am. J. Obstet. Gynecol., 69: 1000-6, 1993a.

15.Trofatter, K.F. et al. U se of the fibrin D-Dimer in screening for coagulation abnormalities in preeclampsia. Obst. Gynecol., 73(3): 435-9, 1989.
Endereço para correspondência

Luci Maria Sant'Ana Dusse

Faculdade de Farmácia/UFMC

Av. Olegário Maciel 2.360/608 - Lourdes

CEP 30180-112 - Belo Horizonte-MG

Tel.: (31) $3339-7647$

Fax: (31) 3339-7644

e-mail: lucim@farmacia.ufmg.br 